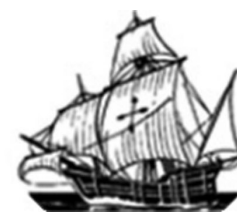

Nau Literária: crítica e teoria de literaturas • seer.ufrgs.br/NauLiteraria

ISSN 1981-4526• PPG-LET-UFRGS • Porto Alegre • vol. 09, n. $01 ・$ jan/jun 2013

Dossiê: Voz e Interculturalidade

\title{
AS PRÁTICAS ORAIS DAS REZADEIRAS: UM PATRIMÔNIO IMATERIAL PRESENTE NA VIDA DOS ITABAIANENSES
}

\author{
Danielle Gomes do Nascimento \\ Proling/UFPB \\ danielllegy@yahoo.com.br \\ Maria Ignez Novais Ayala \\ Proling/UFPB \\ ignez_ayala@uol.com.br
}

\section{RESUMO}

As rezadeiras, também conhecidas como benzedeiras, possuem uma importante função na parcela da sociedade que mantém usos e costumes tradicionais: estabelecer relações com o sagrado. Essa tradição tem a oralidade como carro chefe. Detentoras de um grande saber religioso são capazes de, por meio das rezas e dos rituais, curar males e devolver o equilíbrio emocional e físico àqueles que as procuram. $\mathrm{O}$ ofício que exercem é transmitido de geração a geração, de maneira que a pessoa que aprendeu ou foi escolhida para exercer tal ofício também repassará, algum dia, seus saberes a seu sucessor ou sucessora. A continuidade dessa cultura contribui para a preservação do patrimônio cultural, configurado em suas dimensões intangíveis. No que se refere ao patrimônio imaterial, eixo norteador do trabalho, diz respeito às praticas e domínios de saberes, ofícios, valores e a diferentes formas de expressão que compõem a vida social de base comunitária. Este artigo está centrado no oficio de duas rezadeiras populares da região itabaianense, etapa inicial de um trabalho de pesquisa de campo, mais amplo, que está se desenvolvendo em Itabaiana - PB: por um lado, resultará em tese de doutorado e outros estudos acadêmicos; por outro, buscará sensibilizar instituições locais para que o ofício de rezadeira seja reconhecido como patrimônio imaterial. As práticas orais das rezadeiras serão apresentadas a partir dos relatos, memórias e performances. Para esta pesquisa está se utilizando gravação de som e imagem, de modo a dar ênfase às vozes das rezadeiras que, durante o processo dialógico estabelecido com a interlocutora que as procurou (neste caso, Danielle Gomes do Nascimento) presentificam lembranças e práticas religiosas. As duas rezadeiras contaram um pouco da vida religiosa, da pratica com as rezas e outros afazeres. A pesquisa parte do conhecimento empírico das rezadeiras a fim de apreender os significados do fenômeno social praticado por elas - da cura por meio das rezas. O trabalho está embasado nos princípios definidos pelo IPHAN (Instituto de Patrimônio Histórico e Artístico Nacional) para identificação do Patrimônio Imaterial Brasileiro e autores que reconhecem a importância da memória na coletividade - Bergson (2011), Halbwachs (2006), Bosi (2004), autores que fornecem subsídios para os estudos da oralidade e estudos linguísticos - Ong (1998), Zumthor (2007) e Bakhtin (2010), entre outros. Portanto, as rezadeiras ou benzedeiras estão presentes nos costumes tradicionais da religiosidade brasileira e têm sido identificadas como detentoras de saberes e por seu oficio apreendidos e aprendidos por meio de transmissão oral. 
Palavras-chave: Patrimônio Imaterial, rezadeiras, oralidade

\title{
THE ORAL PRACTICES OF THE PRAYERERS: AN IMMATERIAL PATRIMONY PRESENT IN THE LIFE OF PEOPLE FROM IBABAIANA
}

\author{
Danielle Gomes do Nascimento \\ Proling/UFPB \\ danielllegy@yahoo.com.br \\ Maria Ignez Novais Ayala \\ Proling/UFPB \\ ignez ayala@uol.com.br
}

\begin{abstract}
The prayerers, who in Brazil are also known as "benzedeiras", a term that in English could be translated as the "blesserers", play an important role in a part of a society that keeps uses and traditional habits: establish relationship with the sacred world. Such tradition has orality as a key-practice. These prayerers possess a great religious knowledge and are able to put away evil and restore both emotional and physical balance by saying a set of prayers and rituals to the ones who seek them asking for help. The activity they exert is passed generation after generation, in a way the person who learned such task or was chosen to carry on such practice will also transmit his or her knowledge to the sucessor. The persistence of such culture contributes to the maintainance of the cultural patrimony, configured in its untangible dimensions. Regarding immaterial patrimony, a central point in this research work, refers to practices and domains of the knowledge, tasks, values and diferente ways of expression that constitute the social life of a communitary base. This article is centered in the task of two popular prayerers in the region of Itabaiana, an introdutory phase of a wider research work being developed in the city of Itabaiana, located in the state of Paraíba, northeast region of Brazil. This research work will result in a Doctor's Dissertation and also other academic production. Parallel to this, this research work intends to atract the sensitiveness in local institutions so as the prayerers practice be acknowledged as immaterial patrimony. The oral practices of the prayerers are presented in narrations, memories and performances. This research work counts with both áudio and visual resources, as a way to emphasize the voice of the prayerers, who in a dialogical process with her interviewer (Danielle Gomes do Nascimento) bring to presente rememberings and religious practices. Both prayerers narrated a litle bit of the religious life, the prayers practice and other tasks. The research work starts from empiric knowledge of the prayerers, in order to learn the meanings of the social phenomenon performed by them, i.e. the heal promoted by certain prayers. This discussion adopts as reference the principles established by the National Artistic and Historic Patrimony, IPHAN (an acronym from Instituto de Patrimônio Histórico e Artístico Nacional to identify the Brazilian Immaterial Patrimony and also authors who recognize the importance of memory in colectivity, such as Bergson (2011), Halbwachs (2006), Bosi (2004), as well as authors who provide subsidy to studies about orality and linguistic, Ong (1998), Zumthor (2007) and Bakhtin (2010) among others. Thus, the prayerers or blesserers are present in
\end{abstract}


traditional habits of Brazilian religiousness and have been identified as the ones who posses certain knowledge in their practices, resulted from learning or oral transmission.

Key Words: Immaterial Patrimony; prayerers; orality

\title{
Como estudar o ofício das rezadeiras e seus saberes
}

A tradição oral apresenta elementos que caracterizam e justificam as diversas maneiras que os indivíduos possuem para transmitir verbalmente seus ensinamentos e compartilhá-los com seus descendentes na sociedade. Estudiosos da oralidade como Zumthor (1993) e Ong (1998) chamam atenção para as práticas orais como o principal meio de difusão das manifestações culturais.

Enveredar pelos caminhos da cultura popular é permitir ser fascinado pela riqueza de conhecimentos que as pessoas mais velhas trazem consigo. Embora o tempo passe, e surjam sempre inovações, entre as quais os recursos tecnológicos que permitem uma comunicação à distância, o conhecimento adquirido pelos mais velhos continua sendo propagado aos amigos, vizinhos e familiares de modo direto, através de conversas. Com isso, os conhecimentos, os valores e as experiências dos mais velhos apresentam uma importante função na sociedade: manter viva a identidade, a memória e a história de vida da comunidade. Segundo BOSI (1994, p.18), "a função social do velho é lembrar e aconselhar - memini, moneo - unir o começo e o fim, ligando o que foi e o por vir".

Eis um dos mais valiosos bens da tradição de um povo, as lembranças guardadas na memória, virtude que os mais velhos têm para compartilhar com seus descendentes. Para $\mathrm{H}$. Bergson,

\begin{abstract}
A memória... não é uma faculdade de classificar recordações numa gaveta ou de inscrevê-las num registro. Não há registro, não há gavetas, não há aqui, propriamente falando, sequer uma faculdade, pois uma faculdade se exerce de forma intermitente, quando quer ou quando pode [...]. Na verdade, o passado se conserva por si mesmo, automaticamente. Inteiro, sem dúvida, ele nos segue a todo instante: o que sentimos, pensamos, quisemos desde nossa primeira infância está aí, debruçado sobre o presente que a ele irá se juntar, forçando a porta da consciência que gostaria de deixá-la de fora. (BERGSON, 2011, p. 47-48)
\end{abstract}

Para o autor, a memória não é simplesmente a ato de recordar, de classificar e registrar determinados momentos da vida; a memória é algo vivo, inteiro, presente a todo instante, sendo retomada a qualquer momento que a consciência for acionada. Assim, as interfaces entre passado e presente são bem próximas, e a memória é o elo que as une. É a partir da 
memória que podemos compreender o presente e as ações realizadas em um determinado momento.

Como se tem observado nas gravações de som e imagem aqui utilizadas, as práticas orais das rezadeiras populares da região itabaianense revelam-se através da presentificação da memória, que muitas vezes suscita performances ao contarem um pouco da vida religiosa, das atividades em que são utilizadas as rezas e outros afazeres.

Em suas narrativas a experiência de vida acumulada se traduz em lembranças de dificuldades extremas - fome, maus tratos, de aprendizado e domínio de outras práticas orais, como os benditos, estórias, cantigas de roda, pastoril entre outras ações presentes na infância dessas rezadeiras ou em outros momentos e situações vivenciados por elas. Ao relatarem um pouco dessas práticas, demonstraram muita satisfação e muita emoção, já que essas práticas foram frequentes em suas vidas.

Nesse aspecto, percebe-se que o contexto religioso é predominante, havendo estreita relação entre cultura popular e religiosidade. BRANDÃO (1980, p. 15) ressalva a melhor maneira de compreender a cultura popular:

Talvez a melhor maneira de se compreender a cultura popular seja estudar a religião. Ali ela aparece viva e multiforme e, mais do que em outros setores de produção de modos sociais da vida e dos seus símbolos, ela existe em franco estado de luta acesa, ora por sobrevivência, ora por autonomia, em meio a enfrentamentos profanos e sagrados entre o domínio erudito dos dominantes e o domínio popular dos subalternos.

A religião, compreendida como componente indissociável da cultura, elemento inerente e espiritual da manifestação do indivíduo, se insere sob dois paradigmas. Em um de seus estudos, Narrativas populares, Xidieh (1993), sociólogo que dedicou grande parte de sua vida à pesquisa da cultura religiosa popular, chama atenção para a estreita relação dos grupos sociais com a religiosidade. Faz uma análise da religiosidade como elemento norteador da vida, sendo transmitida de geração a geração ainda que os significados, funções e finalidades possam variar entre as culturas em que estão inseridas. Segundo AYALA (s/d, p. 11), "as mudanças são uma característica necessária de toda cultura viva". Tal posicionamento nos leva a entender que, o fato de nos referirmos à cultura popular, não quer dizer que estejamos nos referindo a algo estático, mas a modos de expressão e representação que vão se adequando às necessidades sociais e individuais dos grupos de que fazem parte. Em se tratando de cultura oral, as transformações são mais evidentes, tendo em vista que a fala tem um caráter sonoro-auditivo que favorece as mudanças. 


\section{As rezadeiras itabaianenses: representantes do patrimônio imaterial}

O conceito de Patrimônio Imaterial considera a vida social das pessoas, pertencentes a comunidades tradicionais, que têm a transmissão oral como principal meio de repasse de conhecimento de formas de expressão e saberes. A Unesco define como Patrimônio Imaterial as práticas, representações, expressões, conhecimentos e técnicas - junto com os instrumentos, objetos, artefatos e lugares culturais que lhes são associados - que as comunidades, os grupos e, em alguns casos, os indivíduos se reconhecem como parte integrante de seu patrimônio.

No Brasil o reconhecimento do patrimônio imaterial é recente, tendo em vista que, nas últimas décadas, as pessoas, associadas a suas atividades sociais e culturais comunitárias, passam a ser reconhecidas, sendo capaz de contribuir para composição e a permanência da tradição e da cultura através de suas experiências de vida. Segundo o IPHAN, Patrimônio Imaterial é definido como:

Os Bens Culturais de Natureza Imaterial dizem respeito àquelas práticas e domínios da vida social que se manifestam em saberes, ofícios e modos de fazer; celebrações; formas de expressão cênicas, plásticas, musicais ou lúdicas; e nos lugares (como mercados, feiras e santuários que abrigam práticas culturais coletivas).

Para a identificação do Patrimônio Imaterial, pode-se entender a importância das vozes dos detentores desses saberes que narram e demonstram como são suas expressões culturais e artísticas, os ensinamentos e as experiências das pessoas, dos grupos e das comunidades herdadas das gerações anteriores e que são transmitidas às gerações posteriores. Há incontáveis formas de representação desse patrimônio. As rezas populares são um exemplo, por ser um campo do saber que apresenta um arcabouço histórico e antropológico religioso, se constituindo numa prática social que apresenta ensinamentos e domínios específicos, além de ter uma importante função em comunidades tradicionais.

No contexto especifico desta pesquisa, as rezadeiras populares são representantes desse patrimônio, por estarem presentes na vida dos paraibanos, mais especificamente, no diaa-dia dos itabaianense, através de seu grande conhecimento religioso e simbólico. As rezas apresentam uma grande utilidade na comunidade, pois por meio delas muitos problemas são solucionados. As rezadeiras rezam para vários fins: afastar o olhado, espinhela caída, dor de cabeça, cobreiro, vermelhão na pele, engasgamento, para apagar fogo, e até contra algumas 
enfermidades nos animais, enfim, uma prática religiosa emergencial, capaz de atender as necessidades daquele povo.

As práticas culturais por elas relatadas estão diretamente relacionadas às ações vivenciadas pelas pessoas da comunidade, ou seja, se aprende determinada ação porque há no grupo pessoas que já fazem, ou que se preocupam em repassar algum tipo de ensinamento. Nesse caso, há uma relação de pertencimento e identificação com determinada prática. $\mathrm{Na}$ cultura popular, o pertencimento revela a identidade do indivíduo e do grupo. No caso das rezadeiras e das pessoas que a procuram, estas sempre buscam as rezas, pois participam de um contexto em que há necessidade de recorrer ao sagrado para resolver algum tipo de problema físico ou espiritual. Assim, a rezadeira se coloca como parte da comunidade e da história do lugar onde vive através do seu conhecimento adquirido na própria comunidade.

Deve-se ressaltar que, além de dominarem grande número de rezas, as duas rezadeiras que colaboraram com esta pesquisa aprenderam outras práticas orais: cantos religiosos como os benditos, canções presentes em várias formas de expressão (entre elas foram citadas e cantadas algumas músicas de serenata), causos populares, danças como pastoril/lapinha... Essas manifestações orais sempre estiveram presentes na infância e na vida delas, uma vez que essas práticas faziam parte do cenário local, servindo de referência na identificação dos costumes daquela comunidade.

Portanto, ao tratar de patrimônio imaterial não podemos esquecer que são bens vivos, sujeitos a mudanças e reorganização constantes, expressos através de ações culturais de base oral, de lembranças relatadas pelos mais velhos e que fazem parte da diversidade cultural brasileira.

\section{As práticas orais das rezadareiras itabaianenses}

Ressaltamos, até aqui, o fato de o Patrimônio Imaterial estar relacionado a domínios da vida social, propagados através de conhecimentos e experiências adquiridos e repassados na comunidade onde vivem integrantes de comunidades tradicionais. As práticas orais tornam-se um dos meios de preservação da tradição, da cultura e, portanto, contribuem para a conservação do Patrimônio Imaterial. Entretanto, é necessário reconhecer as práticas orais enquanto enunciados concretos, únicos, pertencentes a um campo específico da atividade humana e que por sua vez, se utilizam da linguagem para tornar públicas as experiências e os conhecimentos que são repassados. No que se refere à função da linguagem, BAKHTIN (2003, p. 261) defende: 
Todos os diversos campos da atividade humana estão ligados ao uso da linguagem. [...] o emprego da língua efetua-se em forma de enunciados (orais e escritos) concretos e únicos, proferidos pelos integrantes desse ou daquele campo da atividade humana.

Assim, é por meio da linguagem, que as atividades humanas são realizadas, que enunciados se concretizam e produzem significados de acordo com o que os integrantes do grupo pensam, dizem, creem. O que é proferido identifica o modo de vida de cada grupo. $\mathrm{O}$ autor enfatiza que os enunciados são sempre únicos. Em "Para uma filosofia do ato responsável", o autor reconhece a unicidade do discurso como um importante meio para a identificação de um ato enquanto evento:

$\mathrm{O}$ ato - considerado não a partir de seu conteúdo, mas na sua própria realização - de algum modo conhece, de algum modo possui o existir unitário e singular da vida; orienta-se por ele e o considera em sua plenitude[...]. (BAKHTIN 2012, p. 79).

O autor também estabelece uma correlação entre a categoria de experiência vivida e a de unicidade:

A categoria da experiência vivida no mundo-ser real - enquanto evento - e a categoria da unicidade. Experienciar um objeto significa possuí-lo como unidade real, mas tal unicidade do objeto e do mundo pressupõe a correlação com a minha própria singularidade. (BAKHTIN, 2012 p.102)

Nesse sentido, as rezadeiras, ao proferirem seus discursos, através de seus relatos e suas memórias nos ajudam a compreender como cada experiência é única e ao mesmo tempo é de todos, no sentido de que é possível conhecer determinados posicionamentos pessoais e até mesmo a história social da comunidade. Contudo, cabe apresentar as práticas orais das rezadeiras, nossas colaboradoras, Dona Severina ou Dona Gorda, como gosta de ser chamada, e Dona Josefa, conhecida como Dona Zefinha, com saberes únicos adquiridos desde a infância e que perduram até hoje em suas vidas e em suas memórias.

\section{As práticas orais da rezadeira Dona Gorda}

Dona Severina, senhora de setenta e três anos, reside em Itabaiana, no bairro Açude das Pedras. Relatar um pouco de si e um pouco do que aprendeu foi prazeroso para ela, pois foi um momento de repensar fatos marcantes na sua vida. À medida que ia contando os fatos, os seus sentimentos oscilavam - alegria, tristeza, saudade, raiva, enfim, os sentimentos eram 
aflorados ao lembrar-se de determinados momentos. Sobre o ato de lembrar, BOSI (1994, p. 55) defende:

$\mathrm{Na}$ maior parte das vezes, lembrar não é reviver, mas refazer, reconstruir, repensar com imagens e ideias de hoje, as experiências do passado. A memória não é sonho, é trabalho [...]. A lembrança é uma imagem construída pelos materiais que estão, agora, à nossa disposição, no conjunto de representações que povoam nossa consciência atual. Por mais nítida que nos pareça a lembrança de um fato antigo, ela não é a mesma imagem que experimentamos na infância, porque nós não somos os mesmos de então e porque nossa percepção alterou-se e, com ela, nossas ideias, nossos juízos de realidade e de valor.

Nossa colaboradora lembra que era chamada desde criança por "gorda", nome que até hoje é conhecida. Relata que teve uma infância sofrida, trabalhando na plantação de cana, na criação de animais e ajudando nas atividades domésticas, em Pernambuco. Sua mãe teve cinco filhos e ela era a caçula. Como sua mãe ficou viúva muito jovem, casou-se de novo, passando a se preocupar apenas com o marido, e deixando assim, os filhos em segundo plano. Todo sofrimento fez com que Dona Severina abandonasse a casa materna ainda na infância, aos dez anos. Veio para a cidade de Itabaiana trabalhar como doméstica, "em casa de família", como ela diz. Essas lembranças deixaram-na um pouco triste. Segundo BOSI (1994, p.47):

A memória permite a relação do corpo presente com o passado, e ao mesmo tempo, interfere no processo "atual" das representações. Pela memória, o passado não só vem à tona das águas presentes, misturando com as percepções imediatas, como também empurra, "desloca" estas últimas, ocupando o espaço todo da consciência. A memória aparece como força subjetiva ao mesmo tempo profunda e ativa, latente e penetrante, oculta e invasora.

Morando em Itabaiana, passou a conviver mais com sua avó, que morava em um povoado próximo a cidade. Ia visitar a avó todo final de semana, pessoa a quem tinha muito respeito, apesar de maus tratos (mencionou que também apanhava muito da avó, como ocorria, antes, quando estava na casa do padrasto e da mãe). Sua avó é a principal responsável pelos ensinamentos orais religiosos. Além das rezas, aprendeu bendito - orações cantadas na igreja da qual participava.

Dona Gorda acompanhava muito sua avó, afirmando que para onde sua avó ia, a levava junto e esclarece: "Dos netos dela, quem fazia afago a ela só era eu, só era eu". Desde 
os oito anos de idade, Dona Severina passou a ficar mais atenta aos ensinamentos de sua avó. Sobre os ensinamentos das rezas confirma:

"E a reza eu aprendi, minha avó rezava espinhela caída, ventre caído, peito aberto, dor de cabeça, carne triada, isso aprendi com minha avó. Quando não era na igreja, todo dia tinha um terço na igreja, e eu rezava, e fiquei até a data de hoje".

Fala com satisfação sobre a grande sabedoria que tinha sua avó, principalmente no ato pragmático/ilocucionário de dizer algo sobre alguém ou sobre alguma coisa. No relato, fala que sua avó sabia apagar o fogo com reza. Dona Severina diz como sua avó fazia para apagar fogo:

"Fogo, o fogo podia tá em cima, ela levantava a mão... e baixava. [...] $\mathrm{O}$ povo morava em casa de palha, às vezes as crianças se descuidavam e butavam fogo. O povo corria e mandava chamar ela, e aí, de casa mesmo ela (acena com a mão) e o fogo baixava".

Além de saber apagar o fogo, sua avó resolvia muitos outros problemas com as rezas. Lembra que sua avó tinha uma devoção de toda sexta-feira rezar para afastar pragas, pestes, insetos e outros bichos daninhos. Toda sexta para o sábado sua avó rezava e ela mesma respondia. Quando era por volta da quatro horas da madrugada ela andava pelo meio da casa dizendo: "ô de casa, ô de casa, mandou dizer nosso senhor Jesus Cristo que quem e [= aí] não rezasse de fé, de fome se arretirasse dessa casa". Dona Severina assevera a eficácia da reza:

"Na casa dela num tinha um mosquito, na casa dela num tinha uma mosca, na casa dela num tinha formiga, essa tal de muriçoca, grilo, num tinha nada na casa dela, nada, nada. Se a senhora butasse um roçado, tava cheio de largata. O povo chegava, 'mas madrinha', o outro, 'mas comadre eu vou perder minha lavoura, porque compadre ói comadre é tanta da largata, eu to aguando e não tem jeito'. 'Deixe pra lá, mas elas vão se acabá'. Quando dava três horas ela saía, com essa cruz e essa toalha, nos quatro canto do roçado. Pronto, ali, quando era no outro dia que o compadre chegava lá, o dono do roçado, tava coalhado de lagarta. Num tinha um grilo pra furar essa lavoura, num tinha nada."

Também sabia a reza para retirar "resto de parto" que ficava no útero das mulheres, pois além de rezadeira, também era parteira. Com orgulho, afirma:

"Mulher, ela era parteira, se o cumpadre fosse buscar ela, a mulher tivesse que morrer de parto, que ela não dava jeito, ela nem ia, ela dava uma desculpa e tudo e num ia, porque ela sabia que a mulher ia morrer..." 
Dona Severina também aprendeu com sua avó os benditos cantados no mês de maio. Como convivia muito com sua avó, aprendeu a admirar os preceitos religiosos da Igreja Católica, já que sua avó era muito atuante na Igreja:

"Ela rezava o mês do maio, 32 noites, ela rezava e eu rezava todas as 32 noites com ela, o que ela rezava eu acompanhava". [...]. Hoje é, ah um mês de maio aqui é diferente dos benditos de antigamente. Hoje, o povo reza o mês de maio e não usa a queima de flores... alguma igreja que usa queimá flores".

Dona Severina, canta com emoção alguns benditos que guarda na memória. O bendito de queimar flores:

Que flores são estas que vão se queimando,

é cravos e rosas e rosas é dada

Umbora menina saíres pra fora

Queimar essas flores de Nossa Senhora

Lembra com alegria que após cantar o bendito de queima de flores, havia queima de fogos. Também aprendeu o bendito de beijar o santo:

De dois em dois no pé do altar,

De dois em dois no pé do altar

Se ajoelhar primeiro

Pra poder beijar

Dona Gorda também sabe o bendito cantado no mês de maio a cada notárioº

Com muita alegria

Amanhã de uma noite,

Um coração de Maria

Essas recordações deixaram Dona Severina contente, despertando saudade de um tempo remoto. Para BOSI (1994, p. 53)

A lembrança é a sobrevivência do passado. O passado conserva-se no espírito de cada ser humano, aflora a consciência na forma de imagenslembrança.

Sobre o conceito de imagem-lembrança, Ecléa Bosi se apoia em Bergson ao defender enquanto lembrança pura e que traz à tona da consciência um momento único, singular, não repetido, irreversível da vida (CF. BOSI, 1994 p. 49).

${ }^{1}$ Dá-se o nome de noitaro, no sertão, a pessoa ou ao grupo responsável por aquela noite de novena: as crianças, os jovens, os casados, os solteiros... 
Dona Gorda é uma pessoa de grande importância na comunidade onde mora, por apresentar grande conhecimento e experiência com as rezas de cura. As rezas de cura são tipos de reza da tradição oral popular que é transmitida de geração a geração. Essas rezas são utilizadas para um fim especifico - curar doenças, afastar o "mal" e para proteger as pessoas que estejam sendo ameaçadas por algum tipo de perigo ou enfermidade. Como é muito experiente, sempre é requisitada por aqueles que acreditam, sejam conhecidos ou não; quem a procura busca alívio das dores físicas e/ou espirituais a fim de curar olhado, espinhela caída, dor de cabeça, vermelhão na pele, cobreiro, entre outras. Um saber que não aprendeu na escola, mas no dia-a-dia com sua avó, através dos sentidos - vendo, ouvindo, pegando, sentindo. Pessoas como Dona Severina aprenderam determinadas práticas orais e carregam consigo até os dias de hoje, estando sempre a postos para ajudar aqueles que necessitam.

\section{As práticas orais da rezadeira Dona Zefinha}

Dona Josefa, conhecida na comunidade por Zefinha tem setenta e quatro anos e também mora em Itabaiana, no bairro Jucuri. Guarda em sua memória lembranças de algumas práticas orais que aprendeu no decorrer de sua vida, da qual relata alguns fatos importantes. BOSI (1994, p. 85) afirma que a arte da narração não está confinada nos livros, seu veio épico é oral. O narrador tira o que narra da própria experiência e o transforma em experiência dos que escutam.

Da infância, Dona Josefa guarda momentos tristes, pois trabalhou muito ajudando nos afazeres domésticos, cuidando dos irmãos, na agricultura, além das dificuldades de locomoção já que tinha que atravessar o rio para chegar ao centro da cidade. Lembra:

"Foi bem boa não minha mocidade não, trabalhei muito no roçado do povo, trabalhei muito no roçado do povo, aqueles sacos de algodão de lado, apanhando fava, apanhando algodão, descapelando amidubim, sofri muito, atravessar esse rio cheio de água nos cavalete, quando num era, o rio baixava mai, a gente atravessava a braço, o povo dizia que a gente ia morrer afogado, era assim..."

$\mathrm{Na}$ adolescência, aconteceu um fato marcante - a morte de seu pai, o que acarretou mudanças depois desse acontecimento. Vejamos o mais lhe marcou:

"Meu pai morreu em 49, aí pronto a gente ficou no meio do mundo a pisar casca de angico, pros cortumes pra curtir couro de boi, aí era com um martelo, uma enxada, cerrado um pedaço de cabo deste tamanho numa pedra, cada uma casca que era dessa largura, acho que é por isso que eu vivo doente". 
Após a morte de seu pai, sua mãe assumiu a responsabilidade de cuidar dos seis filhos, tendo que trabalhar para sustentar a família e Dona Zefinha, com 13 anos, tinha que ajudar a cuidar dos irmãos mais velhos. Como morava no bairro chamado Campo Grande, situado em um dos lados do rio que percorre o município de Itabaiana, tinha que atravessar um longo percurso para trabalhar. Sua mãe decidiu morar perto da mãe dela, avó de Dona Zefinha, do outro lado do rio, para evitar a distância e não deixar seus filhos tão longe da família. Lembra:

"Aí ela foi e alugou a casa do outro lado do rio, a Tonzinho, o sogro de Lula do mangaio, alugou a casinha por vinte mi réi, naquele tempo era mi réi, era vinte mi réi. Aí a gente se mudou, a gente tudo contente, tudo feliz, tudinho porque ia morar no outro lado do rio, pra ficar perto de minha avó, aí a gente foi. Aí de lá, a gente começou pisano casca, lavava roupa mai a minha mãe".

Para Dona Zefinha, esse momento foi marcante, pois indica uma nova etapa, a alegria toma conta da família pelo fato de morar em outro lugar, mais perto de sua avó. Para se referir ao proprietário da casa onde morou, faz referência a pessoas que a própria comunidade designou "Lula do mangaio", pessoa que tem uma casa de comércio de artigos populares. Reconhecer as pessoas a partir de suas características, de uma referência ou indicando um grau de familiaridade são marcas comuns entre as pessoas do interior. No caso de Dona Zefinha, ela procurou várias vezes, estabelecer diálogo com a pesquisadora que estava gravando, tentando identificar experiências comuns; com isso, sua fala acabou trazendo sua interlocutora para dentro de seu relato, ou, utilizando a terminologia de Bakhtin, traz o outro para seu discurso, como veremos adiante.

Uma vez estabilizada naquele local, Dona Zefinha começa a criar laços afetivos na vizinhança, passando a dividir bons momentos, como as brincadeiras na calçada da casa de sua avó. Lembra com alegria:
"Aí quando a gente completou catorze anos, a calçada da casa da minha avó era alta, aí se ajuntou eu, Leninha, do ministro que é, ela é do ministro da igreja, sabe quem é Leninha, se ajuntou eu, Leninha, Lúcia irmã, Marilete irmã de Leninha, a minha irmã Nevinha, e a minha irmã Maria José, aí a gente brincava de roda, cantava: 'A dança da carranquinha é uma dança deliciosa, que põe o joelho enterra as moça fica formosa. Nevinha levanta os braços, Nevinha sacode a saia, Nevinha tem dó, de mim Nevinha me dá um abraço'. Ela abraçava a gente, a gente ficava dentro da roda e ela saía".

Sobre a capacidade de relacionar os sentidos durante a comunicação, BAKHTIN (2003, p. 348) defende: "viver significa participar do diálogo: interrogar, ouvir, responder, 
concordar, etc. Nesse diálogo, o homem participa por inteiro e com a vida: com os olhos, os lábios, as mãos, a alma, o espírito, todo o corpo, os atos".

Além das brincadeiras de roda, Dona Zefinha também brincava de lapinha. Ao remeter à lapinha, lembra-se da pessoa que a ensinou a rezar. Vejamos:

"Aí a gente inventou de brincar uma lapinha. Aí na calçada tinha Dona Maria, do seu finado Vicente, que a mãe dela foi quem me ensinou a rezar, tava com noventa anos quando ela começou a me ensinar a rezar. Naquele tempo eu era nova tudinho e num ligava com nada[...]. ela era vizinha, porque a gente se mudou pra perto dela, e ela gostava muito de mim, dizia que eu era uma menina pra frente, que não tinha vergonha... de nada. aí a gente foi brincar de lapinha. Aí essa Dona Maria que era esposa de Seu Vicente, ia pra feira, aí comprou um vidro assim de areia prateada pra enfeitar meu vestido, que ela gostava muito de mim. Ela dizia que no meio de tudinho, só tinha eu. Aí enfeitaram os vestido da gente tudinho".

Como não era permitido ir a festas, as pessoas da rua se reuniam na calçada para brincar, conversar ou dançar. Lembra-se da dança da lapinha que organizavam perto de casa, já que gostavam muito de brincar e dançar:

"Aí a gente fazia uns ramalhete, ela fazia, a véia, fazia uns ramalhete bem bonitinho assim, butava peufume pra gente oferecer, né[...]. Minha fia... enchia assim de gente, oh, de gente, de gente pra assistir".

Esta dança está relacionada, em sua memória, a uma antiga paixão, pois na brincadeira, seu amado costumava colaborar para que Dona Josefa e seu grupo ganhassem. Em troca era oferecido um ramalhete.

"E elas tudo oferecendo os ramalhete dela, né, oferecendo. Aí minha tia disse assim, 'oh, que que tu tem Zefinha oferece a Vavá, tu soi uma menina já vai fazer quinze anos, e ele já tem dezessete pra dezoito'. Eu digo, 'mas num fale isso pelo amor de Deus, não mode minha mãe'. Aí fizeram assim: dois mi réi pra descer o encarnado e subir o azul. As menina tudo veia de dezoito, dezenove anos, as minhas irmãs mais velha né, fizeram as bandeira. $[\ldots]$ “

Lembra com alegria de momentos vivenciados na lapinha, entre eles, diálogos com o rapaz por quem tinha afeição, mesclados com cantos e com as partes de intervalo da dança dramática em que as meninas vendem ramalhetes para a plateia e conquistam pontos para os cordões azul ou encarnado. Um exemplo deste fluxo da memória:

"Aí eu cheguei e disse, eu vou oferecer: - Senhor Vavá queira aceitar um lindo ramalhete que a Contra-Mestra dá...(eu era a Contra- Mestra) Aí eu fui né, levei o ramalhete e entreguei-le. Aí ele chegou e disse: - Você é do azul ou do encarnado? Aí eu: - Eu sou do encarnado. Aí ele disse assim: - Cinco cruzeiro pra descer o azul e subir o encarnado, ele. Aí, eu chegei butei o ramalhete aqui, ele butou no bolso e disse assim: - Senhor Vavá estou muito 
agradecida pela bonita ação que o senhor fez comigo, Senhor Vavá estou muito obrigada desceu o azul e subiu o encarnado. Aí o povo hehehe"\}

Dona Zefinha também guarda na lembrança a serenata cantada em nome de seu pretendente para homenageá-la, despedindo-se dela, pois faria uma grande viagem ao Rio de Janeiro, deixando-a a sua espera. No relato, relata sua emoção e exemplifica com um dos trechos de uma música a ela dirigida, durante a serenata:

"Aí quando eles foram chegando perto na casa da minha avó, aí eu enxuguei os olhos eles cantavam, que ele mandou."

Dona Zefinha começa, em seguida, a cantar:

"Eu vou fazer uma viagem longe, longe, bem longe de ti, vou me ausentar. Só te peço queridinha de minha alma que não se esqueça de mim, por onde andar. Eu sou filho das águas mais fortes e sou neto das ondas do mar. Eu só te peço queridinha de minha alma que não se esqueça de mim por onde andar".

Como o rapaz, Vavá, já havia viajado, pediu a um amigo que fizesse uma serenata em seu nome. Um momento de grande emoção para Dona Zefinha. Depois de ter narrado que ela e Vavá, antes da viagem, tinham trocado objetos, para cada qual conservar a lembrança do outro - ele lhe dera um lenço e ela, uma medalhinha -, lembra-se da música cantada para ela naquela serenata que se correlaciona à troca de presentes. Conforme sua explicação, a canção foi escolhida por ele e canta:

"Guarde o lencinho branco/Que esqueceste ao me abandonar
Manchado assim pelo camim que eu/Tirei dos meus lábios quando te
beijei/Guardei teu lencinho, para não me lembrar/Os beijo que nele
deixamos ficar/Eu vejo os teus lábios/ chorar, recordar e depois partiste pra
não mais voltar/Lenço branco foi aquele louco amor/ tudo agora és solidão/
para quem não volta mais/Lencinho amigo, comigo ficou,tu és companheiro,
não me abandonou/lencinho amigo, que eu hei de fazer/aquele carinho não
posso esquecer/A tarde estava fria, frio também ficou teu coração/ que ao
compreender que ele partisse/ no branco lencinho, chorei traição'.

A experiência com as músicas de serenata, Dona Zefinha deve ao seu pai que gostava de cantar esse estilo. Além das práticas orais relatadas, ela sabe de muitos causos, histórias antigas que sua tia lhe contava, além de rodas de coco, entre outras ações.

Percebe-se assim, que Dona Zefinha guarda muitas lembranças da infância e da juventude, de maneira que as suas lembranças estão sempre relacionadas a práticas orais que faziam parte de sua vida, do seu dia-a-dia, cujos conhecimentos foram adquiridos com amigos, vizinhos e familiares. 


\section{Algumas considerações finais}

Dona Gorda e Dona Zefinha estão nos ajudando a conhecer um pouco sobre seu ofício e rezas itabaianenses. Desde os primeiros registros apresentaram experiências de vida, saberes, e domínios específicos, variando de acordo com suas vivências e contextos sociais. Procuramos, através dos trechos citados, destacar as experiências e alguns dos saberes transmitidos oralmente, de modo a evidenciar como passamos a conhecer um pouco do passado de cada uma, e, consequentemente, entender como esses saberes estão relacionados à sua prática de rezadeira, tendo em vista que o domínio das rezas de cura estão no mesmo plano dos outros saberes, conservam-se no plano da memória junto com outras lembranças e afloram sempre que solicitados.

Nesse sentido, Zumthor estabelece uma relação entre memória e transmissão oral, como uma relação de causa e consequência. O autor afirma: "esse interesse pela memória, continuamente manifestado pelos doutos, deve-se ao imenso papel desempenhado nessa cultura pelas transmissões orais - trazidas pela voz (1993, p.140)". E ressalva: "a memória por sua vez, é dupla: coletivamente, fonte de saber: para o indivíduo, aptidão de esgotá-la e enriquecê-la (idem, p.139)”.

Portanto, as rezadeiras estão presentes nos costumes religiosos tradicionais, merecem ser identificadas como detentoras de saberes e por seu oficio ser transmitidos por meio de transmissão oral. O reconhecimento das rezadeiras por seu ofício e saberes tradicionais, como representantes do patrimônio imaterial de Itabaiana é justo e necessário para evidenciar a existência dessa prática enraizada na cultura oral deste município paraibano e em plena vitalidade nesta e em muitas localidades urbanas e rurais do país.

\section{REFERÊNCIAS BIBLIOGRÁFICAS}

AYALA, Marcos. Cultura popular e eventos institucionais: alguns elementos para reflexão. In: EMBARCANDO NA NAU CATARINETA: Tópicos para discussão em literatura, história e memória cultural.

BAKHTIN, Mikhail. Para uma filosofia do ato responsável. [tradução aos cuidados de Valdemir Miotello \& Carlos Alberto Faraco]. São Carlos: Pedro \& João Editores, 2010.

Os gêneros do discurso. In: Estética da criação verbal. Tradução feita a partir do francês de Maria Hermantina Galvão G. Pereira: São Paulo, Martins Fontes, (1979/1992).

BERGSON, Henri. Memória e vida. 2. ed. São Paulo: Editora WMF Martins Fontes, 2011. 
BOSI, Ecléa. Memória e sociedade: Lembranças dos velhos - 3. ed - São Paulo: Companhia das Letras, 1994.

BRANDÃO, Carlos Rodrigues. Os deuses do povo. São Paulo: Editora S.A., 1980.

HALBWACHS, Maurice. A memória coletiva [Tradução: Beatriz Sidou]. São Paulo: Centauro, 2006.

XIDIEX, Oswaldo Elias. Semana Santa cabocla. Instituto de Estudos Brasileiros. São Paulo Brasil-1972.

Narrativas Populares: Estórias de Nosso Senhor Jesus Cristo mais São Pedro andando pelo mundo. São Paulo: Editora da Universidade de São Paulo; Belo Horizonte: Itatiaia, 1993.

ZUMTHOR, Paul. A letra e a voz. [Tradução: Amalio Pinheiro, Jerusa Pires Ferreira]. São Paulo: Companhia das Letras, 1993. 